\title{
Percutaneous angioplasty of the right and left main coronary and the left subclavian arteries in a patient with multilevel atherosclerosis
}

\author{
Jakub Podolec ${ }^{1}$, Jakub Baran' ${ }^{1}$, Łukasz Niewiara ${ }^{1}$, Tomasz Muszyński², Krzysztof Żmudka' ${ }^{1}$, Piotr Pieniążek ${ }^{1}$ \\ 'Department of Interventional Cardiology, Jagiellonian University Medical College and John Paul II Hospital, Krakow, Poland \\ 2Jagiellonian University Medical College, Krakow, Poland
}

Multilevel atherosclerosis is an inflammatory disease that often occurs in high-risk patients in an ageing population [1, 2]. Percutaneous treatment is a challenge for interventional cardiologists but is becoming more frequently recommended in patients with diffuse atherosclerosis [3, 4]. A 65-year-old female patient with hypertension, obesity, dyslipidaemia, and stable angina, who was treated with primary percutaneous coronary intervention (PCl) of the left anterior descending artery (LAD) and the right coronary artery (RCA) 18 years ago, was admitted to the our department with stable angina class II/III according to the Canadian Cardiovascular Society classification and left subclavian artery (LSA) steal syndrome. Coronary angiography showed diffuse atherosclerosis with critical stenosis of the RCA, the left main (LM) artery, the LAD, and the left circumflex artery (LCX). The significance of the LM stenosis was confirmed by intravascular ultrasound (IVUS) which revealed a minimal lumen area of $4.6 \mathrm{~mm}^{2}$ (Fig. 1). According to the Heart Team recommendations, the patient was referred for staged PCI of the RCA and the LM/LAD/LCx. Successful PCl of the RCA with Resolute Integrity ${ }^{\mathrm{TM}}$ (Medtronic, Minneapolis, MN, USA) drug eluting stent (DES) implantation was performed during the initial hospitalisation. One month later, the second stage of IVUS-guided revascularisation of the LM/LAD/LCx was performed, with the implantation of two Resolute DESs $(3.0 \times 18 \mathrm{~mm}$ and $3.5 \times 18 \mathrm{~mm}$ ). The "kissing balloon" angioplasty was done and the proximal optimisation technique was used to optimise the bifurcation result. IVUS measurements confirmed the correct stent placement (Fig. 2). The ultrasound revealed a critical lesion in the LSA and significant subclavian steal syndrome with retrograde flow in the left vertebral artery. The patient was admitted again in order to undergo angiography of the subclavian and cerebral circulation. It revealed multiple atherosclerotic plaques in the aortic arch with critical stenosis of the LSA ostium. Percutaneous angioplasty of the ostial LSA lesion, with pre-dilatation using a Sterling 5.0/20 mm balloon (Boston Scientific, Marlborough, MA, USA) and Omnilink 8.0/19 stent (Abbott, Abbott Park, IL, USA) implantation, was performed. We observed normal cephalic flow through the left vertebral artery (Fig. 3). Staged percutaneous interventional procedures in patients with multilevel atherosclerosis are becoming more common and safe. Ultrasound is a very useful tool to diagnose multi-level arterial disease in the aortic arch and the peripheral arteries.

\section{References}

1. Hansson G, Robertson AK, Söderberg-Nauclér C. Inflammation and atherosclerosis. Ann Rev Pathol: Mech Dis. 2006; 1(1): 297-329, doi: 10.1146/annurev. pathol.1.110304.100100.

2. Oral K, Ezelsoy M, Ayalp K, et al. Hybrid vascular surgery approaches for multilevel arterial occlusive disease. Heart Surg Forum. 2015; 18(1): E28-E30, indexed in Pubmed: 25881221.

3. Ochała A, Siudak Z, Legutko J, et al. Percutaneous interventions in cardiology in Poland in the year 2014. Summary report of the Association of Cardiovascular Interventions of the Polish Cardiac Society AISN PTK. Postepy Kardiol Interwencyjnej. 2015; 11(3): 177-181, doi: 10.5114/pwki.2015.54009, indexed in Pubmed: 26677356.

4. Iared W, Mourão JE, Puchnick A, et al. Angioplasty versus stenting for subclavian artery stenosis. Cochrane Database Syst Rev. 2014(5): CD008461, doi: 10.1002/14651858.CD008461.pub3, indexed in Pubmed: 24833157.

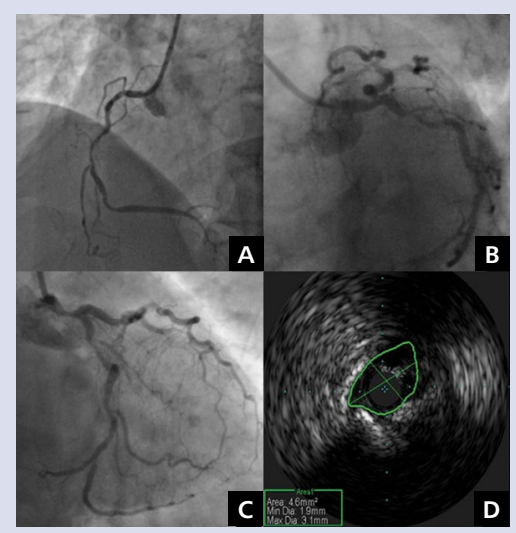

Figure 1. Baseline coronarography of the right and left coronary arteries

$(\mathbf{A}, \mathbf{B}, \mathbf{C})$ and the intravascular ultrasound measurements of the left main coronary artery (D)

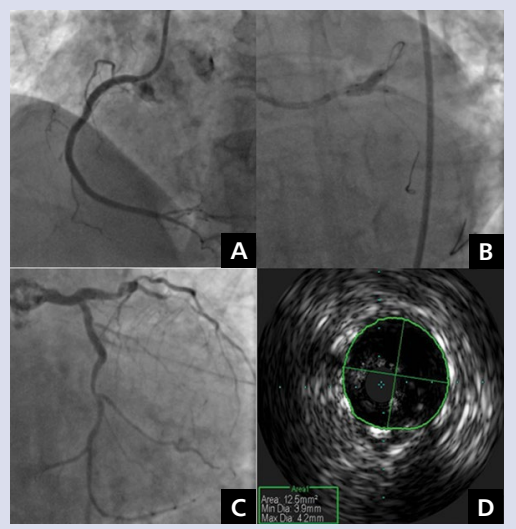

Figure 2. Final angiography of the right coronary artery (A), "kissing balloon" angioplasty of the left main/left anterior descending/left circumflex artery $(L M / L A D / L C X)(B)$, final angiography of the $L M / L A D / L C x(C)$, final intravascular ultrasound of the LM coronary artery (D)

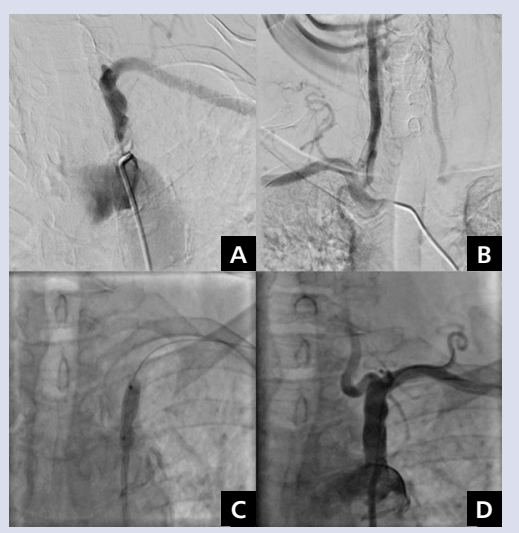

Figure 3. Critical stenosis of the left subclavian artery (LSA) (A) with angiographic proof of subclavian steal syndrome (B), balloon angioplasty of the LSA (C), final, post-stent-implantation result with normal blood flow in the left vertebral artery (D)

\section{Address for correspondence:}

Jakub Podolec, MD, PhD, Department of Interventional Cardiology, Jagiellonian University Medical College and John Paul II Hospital, ul. Prądnicka 80, 31-202 Kraków, Poland, e-mail: jjpodolec@gmail.com

Conflict of interest: none declared

Kardiologia Polska Copyright (c) Polish Cardiac Society 2018 